\title{
"Yes, the type of student supervision matters, but what about the placement structure?" - A critical realist review of block and integrated practice learning models within pre-registration nursing programmes
}

\author{
Phil Coleman* \\ The Open University, United Kingdom
}

Received: July 14, 2020

DOI: $10.5430 /$ jnep.v11n1p39
Accepted: September 9, 2020

Online Published: September 17, 2020

\begin{abstract}
This paper highlights the importance of effective clinical experiences for pre-registration nursing students and the wealth of published work associated with practice learning, particularly regarding approaches to student supervision during a practicum. It draws attention to frequent calls within nursing literature for longer placements; many of which fail to either identify the perceived benefits of such change or state whether a longer practicum should involve increased practice learning hours or redistribute existing hours over an extended period; key omissions given the resource-intensive nature of providing these educational opportunities. It also highlights a paucity of research regarding the effect of placement duration and intensity on clinical learning and that practicum design is commonly shaped by custom, practice, operational and financial considerations rather than a sound educational rationale. A Critical Realist review of studies associated with two fundamental placement structures, the block, and integrated models, is offered to consider their strengths and limitations. Moreover, work that evaluates initiatives offering students paid employment in caring roles undertaken alongside a pre-registration programme and therefore displaying similarities to the integrated practice learning model are examined. The review concludes that, as yet, there is insufficient empirical evidence to recommend the targeted application of either a block or integrated placement model within any specific part of a pre-registration nursing programme, calls for greater consistency in the language of placement structure and outlines the author's own current work contributing to the extremely limited body of knowledge available regarding this aspect of curriculum design within nurse education.
\end{abstract}

Key Words: Block model, Critical realism, Integrated model, Nursing, Placement, Practice learning, Practicum

\section{INTRODUCTION}

Although 'learning in clinical practice is of considerable importance for competence development in nursing education' ${ }^{[1]}$ and direct workplace experiences have been by far the most frequently adopted approach to the clinical education of pre-registration nursing (PRN) students, there continues to be no identified placement model on which to structure such learning that is demonstrably superior to any other; ${ }^{[2-4]}$ hence practicum experiences for nursing students vary widely in both their duration and intensity. ${ }^{[5]}$ Although increased attention is now being given to alternative practice learning models ${ }^{[6]}$ more than 150 years since the first formal nurse education programmes were established ${ }^{[7]}$ there is still only limited evidence available regarding exactly what creates

*Correspondence: Phil Coleman; Email: phil.coleman@open.ac.uk; Address: The Open University, United Kingdom. 
a good placement. ${ }^{[8]}$ As a result, within both nursing ${ }^{[9-12]}$ and other health and social care disciplines ${ }^{[4,13-17]}$ there have been calls for further research to identify the most effective practice learning models.

Various terms are used to describe placement experiences and supervisory practices in clinical education literature ${ }^{[18]}$ but Uys and Gwele ${ }^{[19]}$ argue that there are essentially three different models employed to structure clinical learning experiences within PRN programmes, namely the 'block', 'integrated' and 'internship' approaches. Numerous sub-variants, such as the 'block and dedicated education unit', [20] 'hub and spoke', ${ }^{[21,22]}$ 'pathway' ${ }^{\text {[23] }}$ and 'rotational' models, ${ }^{[24,25]}$ however, are evident. Stephenson ${ }^{[26]}$ asserts that the clinical education framework in a programme is one of three key factors which affect placement learning experiences, the other two being the specific characteristics of the practice learning environment and the quality of student supervision. Nevertheless, many of the different practice learning models described and evaluated in nursing literature, for example the 'clinical education unit', [12] 'clinical partnership', [11] 'cluster', [2] 'collaborative learning unit' ${ }^{\text {'27] }}$ and 'team preceptorship ${ }^{\text {[28] }}$ models, focus solely on the supervisory practices of clinicians and educators and therefore fail to consider any potential influence of the duration and intensity of a practicum on the nature of the student's clinical learning experience. As Cleak and Zuchowski ${ }^{[29]}$ comment, quality supervision can be present or absent in practice education within any placement model and since 'the location and structure of placements may affect outcomes', ${ }^{[30]}$ arguably it is equally important to examine both variables.

\subsection{Block model}

The block model, also termed the 'full-time'[31-33] approach, which in medical education is referred to as a 'clinical clerkship' or 'core clinical rotation', ${ }^{[34]}$ provides dedicated continuous periods of programme time for clinical placement. ${ }^{[35]}$ It is argued that the model allows learners to focus exclusively on practice learning without the competing demands of concurrent academic studies, promotes a richer appreciation of the nurse's role in that setting and makes placement scheduling easier for both the educational institution and the service provider. Nevertheless, it is also suggested that within this model there is an increased risk that academic learning is given insufficient emphasis and becomes crammed between placements, having separate periods of academic and practice learning makes the integration of theory and practice harder, the more intensive practicum risks being regarded by both students and clinicians as work rather than practice learning and learners, more likely to be perceived as full members of the workforce, may even find themselves used simply to offset staffing shortages. ${ }^{[19,32,36]}$

\subsection{Integrated model}

The integrated model is also variously known as the 'distributed', ${ }^{37,38]}$ 'non-block', ${ }^{33,10]}$ 'part-time', ${ }^{[31,39]}$ 'protracted placement' ${ }^{\text {'40] }}$ or 'weekly' practicum. ${ }^{[18,32]}$ It involves PRN nursing students experiencing both academic and clinical learning during almost every week of an identified period during their programme; normally spending one or two days in clinical placement per week and the rest of their time in academic study. The advantages of this model are said to include the potential for greater integration of theory and practice via the opportunity it affords students to reflect upon experiences, assimilate new learning and then immediately apply such learning to practice. It is claimed the framework also offers increased scope for the same teaching staff to contribute to both academic and practice activities, further integrating student learning, and may help to optimise the use of placement capacity. This approach, however, may make placements harder to schedule (especially if the same number of practicum hours are to be achieved) and concurrently exposes students to the demands of practice and academic learning; $[19,32,38,40,41]$ thereby increasing the risk that programme demands become unmanageable for the student.

\subsection{Internship model}

The internship model, also referred to as 'nurse residency', ${ }^{[42,43]}$ which is designed to facilitate 'clinical immersion', ${ }^{[44-47]}$ can be used to complement either a block or integrated practice learning model or to follow a nursing programme which has very limited practice learning experiences. It commonly consists of a practicum which occurs either towards the very end of, or after, the formal programme and in such courses is normally a pre-requisite for graduates seeking professional registration. ${ }^{[19,48]}$ It is claimed that an internship 'allows students to learn new knowledge and skills by being completely immersed and engaged in the prescribed activity', ${ }^{[49]}$ permits students to develop a rich understanding of the practice setting and form stronger working relationships with clinical staff ${ }^{[50]}$ and promotes more effective interprofessional working. ${ }^{[51]}$ Moreover, it is argued such placements can expose learners to new clinical experiences, help them integrate theory and practice, accelerate their learning and facilitate a more effective transition to a Registered Nurse $(\mathrm{RN})$ role. ${ }^{[52-55]}$

Funding an internship, however, can be problematic ${ }^{[56]}$ and in some healthcare disciplines, such as chiropractic care, necessitates that placement costs are met fully or partially by the student. ${ }^{[57]}$ Furthermore, some research undertaken in 
medical education brings into question claims that such immersive experiences necessarily enhance student skills and confidence. ${ }^{[58]}$ Perhaps most importantly, the supplementary nature of the internship model in the context of PRN programmes arguably makes it a secondary consideration; hence this review focuses on the block and integrated placement models as the dominant foundations of practice learning within such curricula.

\section{Critical Realism and the approach TO THE LITERATURE SEARCH AND RE- VIEW}

\subsection{A Critical Realist approach to reviewing literature} Developed in the United Kingdom (UK) by Roy Bhaskar and Rom Harré during the late twentieth century, ${ }^{[59]}$ Critical Realism is a philosophical approach that has achieved 'prominence as an alternative research framework particularly in the social sciences but also in nursing ${ }^{\text {[60] }}$ and one which is 'steadily gathering support for its unique ways of categorizing, highlighting and interpreting phenomena'. [61] In common with more traditional perspectives, such as Positivism, it recognises the existence of a world independent of a researcher's knowledge of it ${ }^{[62,63]}$ and 'treats science as providing the most secure source of knowledge'. ${ }^{64]} \mathrm{Nev}-$ ertheless, it also asserts that reality is 'composed not only of events, states of affairs, experiences, impressions and discourses but also underlying structures, powers and tendencies' ${ }^{[65]}$ Critical Realism proposes two dimensions of knowledge, the intransitive, a world 'independent of what we think of it', and the transitive, or 'our thinking of it ${ }^{\text {'[6] }}$ and that reality has three strata; the 'empirical' level, which includes events that can be observed or experienced, the 'actual' level that is comprised of phenomena which occur irrespective of whether we experience them and the 'causal' level that involves powers, structures and mechanisms which generate events but are not necessarily open to empirical measurement. ${ }^{[67]}$ Moreover, Critical Realists believe the way individuals perceive the world is affected by their social and cultural experiences of which they may not be fully aware or able to set aside in their investigations; hence researchers can never be wholly objective. ${ }^{[68]}$

Given that objectivity is seen as a goal to which one may aspire but can never achieve and causative factors cannot always be measured, Critical Realist research arrives at conclusions based on the principle of 'retroduction'; a process in which a diverse range of evidence is used to formulate the most convincing explanation ${ }^{[69,70]}$ and in so doing enable unobservable events within the causal domain to be knowable. ${ }^{[71]}$ Indeed, this philosophical approach emphasises the importance incumbent upon researchers to provide answers to 'how' and 'why' events. ${ }^{[72]}$ Research from a Critical Realist perspective should also be emancipatory, with a clear focus on seeking to implement positive change. ${ }^{[73,74]}$

Clinical placements are regarded as complex, multidimensional, socio-cultural entities. ${ }^{[75-77]}$ A Critical Realist approach supports academic enquiry in which a diverse range of expert opinion, quantitative and qualitative evidence can be utilised in the quest to better understand phenomena ${ }^{[78,79]}$ and ultimately reach 'reasoned conclusions about how organizations and practices should be'. ${ }^{[80]}$ Critical Realism is therefore 'a particularly relevant philosophical framework on which to base investigations within socially embedded, complex, empowerment focused, practice-based fields such as nurse education'. ${ }^{[81]}$

In a Critical Realist review, also known as an 'integrative review', ${ }^{[79]}$ the author strives to present a case which leads the reader through their arguments whilst always referring to the supporting literature ${ }^{[80]}$ and thereby facilitate third-party evaluation of their assertions. Whilst a traditional systematic review emphasises the number of 'quality' studies that support or challenge a hypothesis and prioritises randomised controlled trials, ${ }^{[82,83]}$ a Critical Realist review is more flexible; seeking to create a coherent argument through the identification and organisation of ideas, theories and $\operatorname{logic}^{[80]}$ as well as highlighting areas worthy of further investigation. ${ }^{[84]}$ This is because the fundamental purpose of such a review is not to provide answers but to stimulate further questions. ${ }^{[80]}$

\subsection{The literature search}

The literature search for this review was undertaken without date range restrictions and was international in its scope to promote information acquisition on a topic in which there is a well-reported paucity of material. It was, however, restricted to English language publications. The search was undertaken in two phases. The first phase sought relevant material from a range of practice-based disciplines and used databases including Academic Search Complete, BioMed Central, the British Library EThOS resource, CINAHL with Full Text, the Directory of Open Access Journals, Emerald Premier, Google, Google Scholar, Internurse, OvidSP Journals, PubMed, Sage Journals Online, Taylor \& Francis Journals Online and library texts. Search terms were generated after professional discussions with academic colleagues involved in nursing and other professional education programmes and, using a snowballing approach, included: 'block', 'distributed', 'fulltime', 'integrated', 'law', 'medicine', 'non-block', 'nursing', 'occupational therapy', 'part-time', 'physical therapy', 'physiotherapy', 'placement', 'practice learning', 'practicum' and 'structure'. 
Lemmatization, field options and Boolean operators, were used to enhance the focus. Terms associated with student supervision during practice learning rather than the structure and intensity of the practicum (for example 'instructor', 'mentor', 'practice assessor', 'preceptor' and 'supervisor'), however, were not excluded from the search.

The second phase of the search focused exclusively on relevant material derived from nursing publications and was undertaken by a literature search specialist in the Library and Archives Service of the Royal College of Nursing (RCN) in the UK. The specialist was advised that the subject under investigation was a "comparison of block and distributed practice learning models in pre-registration nurse education programmes' and that keywords should include 'block', 'distributed', 'full-time', 'integrated', 'non-block', 'part-time', 'placement' and 'practicum'. This part of the search generated an additional two papers relevant to the study.

All research included in this paper was considered against the evaluation criteria outlined by Bonine and Oh. ${ }^{[85]} \mathrm{Con}$ gruent with Critical Realist philosophy, however, the literary evidence employed within this review is not restricted to research findings. Instead, professional opinion and relevant reports are also recognised, deemed to be a meaningful addition to the evidence base and therefore included in the work. Similarly, quantitative, qualitative, and mixed methods research are assigned equal status in respect of their value in contributing to the academic argument.

\section{Results}

\subsection{Effective models of placement structure - observa- tions and opinions}

Donnelly and Wiechula ${ }^{[86]}$ claim that the diverse range of practice learning models identified, described, and evaluated within nursing publications suggests that 'curriculum designers and clinical venues are yet to find an optimum model of education'. Phillips ${ }^{[87]}$ argues that 'there is very little in the literature about the optimal length of practice placements for pre-registration nursing students'; whilst Rohatinsky et al. ${ }^{[3]}$ similarly maintain that 'little evidence is available to guide curricular planners in determining the appropriate and effective use of different clinical models in nursing education' Indeed, it is claimed that many placement models have simply evolved through "custom and practice and in response to industry/professional expectation, ${ }^{[88]}$ and have largely been based on traditional wisdom ${ }^{[89]}$ and 'practical and financial factors rather than pedagogical needs'. ${ }^{[37]}$

Many professional papers and studies within both nursing $^{[20,55,90-96]}$ and other healthcare disciplines ${ }^{[97-99,99]}$ have recommended longer practicum experiences for students.
Nevertheless, it is seldom clear whether such work is advocating longer block placements with an increased number of assigned hours, akin to the 'longitudinal integrated clerkship' increasingly used in medical education, ${ }^{[101,102]}$ or the same number of practice learning hours being distributed over a longer timeframe (i.e. alternative use of an integrated placement model). It could be argued that this lack of clarity masks a more fundamental uncertainty regarding the specific benefits of a longer placement and what mechanisms best enable these benefits to be realised.

For example, if a longer practicum is proposed as a means by which to promote greater student integration within the healthcare team, and in so doing strengthen the learner's clinical confidence and competence, then this may indeed necessitate a block placement with additional practice learning hours. If, however, the main goals of providing a longer placement are to more effectively facilitate student reflection on practice and to consolidate and assimilate academic and practice learning, then this might instead be more efficiently achieved by an integrated model using the same number of practice learning hours within a placement undertaken over an extended period. Given the reminder by Spence et al. ${ }^{[103]}$ that 'clinical education is a critical, yet time and resource intensive aspect of nursing education', such clarification has both important economic and pedagogical implications.

\subsection{Lessons from related fields of investigation}

Although not identical to the concept of an integrated practice learning model, initiatives which provide paid nursing employment to undergraduate student nurses commonly reflect similar characteristics to this model. For example, in Canada, Gamroth et al. ${ }^{[104]}$ evaluated an 'Undergraduate Nurse Employment Demonstration Project' (UNDP) in which third and fourth-year PRN students were offered the opportunity for salaried employment at their educational level under the guidance of a nurse who was supernumerary to regular service staffing; some undertaking this work concurrent to their nursing studies throughout the year. The quasi-experimental outcome evaluation, which involved 173 new nursing graduates, 40 RNs and 7 faculty members involved in the project, concluded that the UNDP enabled the practice performance ability of many participants to rise, increased their confidence and, upon qualification, reduced the transitional period required for them to effectively fulfil their new responsibilities as a nurse. Since there was no specific evaluation of the initiative's impact on the participant's academic performance in their PRN programme and some students were offered UNDP employment in a block during their summer break or a combination of summer block plus additional hours, rather than concurrent work, extrapolation of these findings 
to help establish the potential value of an integrated model of practice learning is inevitably limited.

In Australia, McLachlan et al. ${ }^{[105]}$ evaluated a midwifery employment model in which students on a Bachelor of Nursing/Bachelor in Midwifery dual qualification programme who were also eligible for Enrolled Nurse registration could apply for salaried employment in postnatal wards. This work was undertaken in addition to their university studies but occurred outside any programme clinical placements. The evaluation involved 47 midwives and 9 students who had participated in the scheme and most reported that such provision strengthened working relationships between hospitals, universities and students, enabled learners to acquire a clearer identity within a midwifery team and would more effectively facilitate their transition to a midwife role. Once again, however, since this employment was not concurrent with student placement experiences it does not fully correspond with an integrated model of practice learning.

More recently, Kenny et al. ${ }^{[106]}$ used a mixed methods design to evaluate a 'Registered Undergraduate Student of Nursing' (RUSON) initiative in which second-year PRN students were offered paid employment in a health service over a ten month period for at least 7.5 hours per week (although all participants actually worked 15-20 weekly hours) concurrent to their programme studies under the supervision of an RN. The evaluation involved 56 staff and 39 RUSONs in asynchronous focus groups, surveys involving 80 clients, 61 staff and 16 RUSONs and monthly health service surveys of client outcomes and costs. Although RUSONs reported greater confidence in their practice, acquiring an ability to 'hit the ground running' and feeling part of their clinical team, the concurrent demands of study and employment left some feeling exhausted. Others reported frustration that, in their RUSON role, they could not utilise all the skills they had developed as nursing students and had difficulty returning to this role after placement time in their PRN programme. The question was therefore raised as to whether students might have been more effectively employed as non-registrant Healthcare Assistants (HCAs), rather than RUSONs, since it was perceived that doing so would have offered them a broader practice role.

\subsection{Directly relevant research - no clear preference of model}

A small number of studies have sought to empirically address the effectiveness of block and/or integrated practice learning models within pre-registration healthcare programmes, but their findings have been inconsistent. In the UK, an early survey by Carter ${ }^{[107]}$ compared the quality of supervision for adult branch PRN nursing students offered by either practice

Published by Sciedu Press nurses or health visitors in a primary care placement lasting 10 days. The study involved 19 students and found no clear preference for a block or integrated placement model amongst facilitators. The researcher commented that some respondents 'would have preferred a block placement while others would have liked the days distributed over a longer period' and that 'there was no distribution pattern that seemed to be suitable for everyone'.

Gilmour et al. ${ }^{[108]}$ undertook qualitative research using focus groups comprised of 17 midwifery undergraduates at an Australian university to compare the effect of an integrated placement model (involving two days of practice learning per week) versus a block design (lasting between two and four weeks). Respondents identified a stronger sense of belonging within a clinical team during a block placement. Nevertheless, the researchers noted that students assigned integrated placements in one health authority were often moved between hospitals; hence a reduced sense of belonging for such learners might have been attributable to frequent movement between different teams, rather than the use of integrated practice learning. The minority of students who experienced both types of placement highlighted strengths and weaknesses within each framework; reporting that the block model was more effective in consolidating skills, whilst an integrated structure prevented prolonged periods without practicum experience. The authors concluded that neither placement type was favoured, both models had benefits and disadvantages and continuity when working with midwives was potentially a more significant influence on the quality of practice learning.

Research in Australia by Sheepway et al. ${ }^{[89]}$ involved a quantitative analysis of student competency-based ratings and placement information associated with 56 third-year undergraduates on a speech pathology degree to examine the impact of block and weekly (integrated) placements on competency development. The results of this investigation indicated that student learning increased with each successive placement to the same extent, irrespective of the intensity of each practicum (i.e. the specific model of practice learning), the learner's caseload or the practice setting. The researchers therefore concluded that 'it is the gaining of the experience itself, rather than the intensity of gaining this experience that is important for competency development'.

Quantitative research in Canada by Perry et al. ${ }^{[10]}$ involving 130 second-year PRN undergraduates sought to evaluate the effect of block and non-block (integrated) placement models on student learning perceptions via a questionnaire. Although the results of this pilot study indicated that respondents perceived block placements as slightly more positive 
learning experiences than those based on a non-block framework, this difference was not statistically significant. Further investigation of the two practicum designs to ensure that valuable but limited clinical time within practice learning environments is used to best educational effect was recommended.

A more recent study at an Australian university used focus groups involving 13 preceptors for third-year nursing students ${ }^{[109]}$ to evaluate the implementation of an 'Integrated Clinical Learning Model' (ICLM) for mental health practice experience. Rather than a block mental health practicum lasting 4 weeks normally featuring in the course, learners received a protracted (integrated) placement over 16 weeks during which they concurrently studied a mental health theory unit. Respondents felt it provided a more realistic student experience of mental health nursing practice, reduced levels of learner absenteeism compared to a block placement and provided greater opportunity for students to work alongside staff who had different skills, experience and teaching styles. Nevertheless, respondents also expressed concern that this protracted model reduced continuity for students, made it more difficult for learners to engage with clients, delayed student development of positive working relationships with clinical staff and complicated the preceptor's role in evaluating performance. The researchers therefore concluded that preceptors held mixed views about the implementation of this alternative practicum model.

\subsection{Directly relevant research - support for the block model}

A survey examining placement models provided for students in the clinical education component of professional speechlanguage pathology preparation programmes involving 45 universities in Australia, Canada, Ireland, New Zealand, South Africa, the UK and the United States of America found that such provision was most commonly of a block or weekly (integrated) design. Respondents, however, regarded the block model as the most effective practice learning structure. Whilst the researchers acknowledged a relationship between how often each model was employed and its perceived effectiveness in developing student competence, it was uncertain as to whether efficacy had resulted in uptake of the model or if its use was being retrospectively justified. Arguably, the authors indicated their interpretation of this finding by commenting that "the reported emphasis on student learning outcomes seems contradictory to the reported small influence of learning and teaching research on the adoption of clinical education models' ${ }^{[18]}$

In north-east England, a survey by Coghill ${ }^{[110]}$ evaluated implementation of a Nursing Associate (NA) curriculum to provide a new national second tier of registered practitioner in nursing. It involved $92 \mathrm{NA}$ trainees from 9 healthcare organisations, all of whom were originally employed as HCAs. This study used questionnaires, focus groups and secondary data analysis of demographic and placement models, and found 'there was a mixed placement model approach implemented across the region'. Participants, however, reported a strong preference for block practice learning experiences. Although the researcher did not quantify or attribute this inclination, the report highlighted many students felt 'overwhelmed by the amount of course work and trying to strike a good work/life balance' and some indicated they struggled to uncouple their previous HCA role from their current position as a trainee $\mathrm{NA} ;{ }^{[36]}$ hence the block model may have been perceived by learners as a means by which to help address these challenges.

An Australian study using a mixed methods design involving questionnaires completed by 84 nursing undergraduates and analysis of their university performance records identified that the incorporation of a distributed (integrated) practice learning model within a PRN programme semester appeared to offer no demonstrable benefits. Indeed, introduction of the model necessitated major revisions to the delivery of on-campus teaching sessions, increased workload for some students during the semester and adversely affected both their learning experiences and academic achievement during this programme period. Moreover, learners 'studying within this new schedule showed little inclination to adjust their learning strategies to accommodate the timetable and workload changes' and so the author recommended that students exposed to distributed practice learning should first be assisted to develop self-regulated learning skills if they are to effectively engage with both theory and practice learning. ${ }^{[38]}$

\subsection{Directly relevant research - support for the inte- grated model}

An exploratory qualitative study at an Australian university by Ranse and Grealish ${ }^{[41]}$ sought to 'explore nursing students' experience of learning in the clinical setting of a Dedicated Education Unit using a communities of practice framework'. The research involved data collection from focus groups attended by 25 second and third-year PRN students. This practice learning model involved two days placement per week alongside other student activities within the PRN programme schedule and so, although not described as such, reflects an integrated practicum design. Respondents specifically highlighted that attending the placement for two days each week helped them to become more familiar with the clinical setting and staff, better enabled them to meaningfully contribute to service provision and promoted more effective critical re- 
flection on practice; although the researchers commented they observed little evidence of such critical reflection in the focus groups. Within this study, however, it is impossible to clearly distinguish the extent of any positive effect on the student learning experience derived from the provision of an integrated placement in this setting rather than the nature of the Dedicated Education Unit.

Once again in Australia, Kevin et al. ${ }^{[32]}$ evaluated implementation of a weekly (integrated) placement model for second and third-year PRN nursing students. This model temporarily replaced a full-time (block) practice learning framework normally featuring in the curriculum. Within the trial, secondyear students were allocated two days and third-year students three days of clinical placement per week. During their remaining weekly time, students had scheduled lectures, skills laboratory sessions and tutorials. The new model was implemented over 7 weeks for second-year students and 11 weeks for third-year students. This study involved both qualitative and quantitative analysis of a questionnaire completed by 39 nursing students. Results indicated respondents found the integrated model made it easier for them to understand connections between theory and practice, promoted their familiarity with the placement setting and enabled clinical staff to become more aware of what they should expect from learners. Problems regarding a lack of time, increased fatigue, and disruption to the students' personal lives, however, were also associated with the implementation of a weekly practice learning model. Furthermore, this evaluative study provided no similar data regarding student experiences during a fulltime practicum model, thereby preventing comparison of the two frameworks.

A recent England-wide evaluation of the NA programme by Vanson and Bidey ${ }^{[111]}$ captured data from early, mid-point and end-point surveys of 2,477 NA trainees, a mid-point survey of 531 of their line managers, programme recruitment and attrition records, 'three rounds of deep dive visits to test sites to speak to trainees, patients, supervisors and other local stakeholders' and feedback from attending community of practice meetings at each test site. In contrast to the earlier regional programme evaluation, ${ }^{[36,110]}$ the study found that 59 percent of trainees and 77 percent of their line managers preferred an integrated model of academic and practice learning. This approach was regarded as more effective in facilitating the application of theory to practice, offered more regular interaction with academic staff, provided a better work/life balance and was easier for healthcare employers to accommodate.

During the second phase of an Australian study, Boardman et al. ${ }^{[40]}$ found that 22 second and third-year undergraduates

Published by Sciedu Press enrolled on a Bachelor of Nursing programme who experienced the ICLM reported that it made them feel more like part of the team within the practice setting, allowed them to better reflect on their experiences, consolidate their learning and integrate theory and practice. Indeed, these focus group attendees noted that this model even enabled them to apply new knowledge from academic studies to their placement during the same week. In addition, respondents stated the model allowed them to maintain their work/life balance more effectively by making it easier to undertake paid employment to support their family life and programme studies. The researchers, however, conceded that it was unclear whether some perceived benefits of the ICLM were attributable to the intensity of the practicum or the nature of placement supervision. Furthermore, although these students had previously undertaken block placements in older peoples' services and acute care, no comparison with a block mental health practicum was provided.

\subsection{Directly relevant research - preference for model shaped by student experience/circumstances}

A questionnaire completed by 210 students enrolled on one of four undergraduate PRN programmes in two Canadian provinces identified that first and second-year students tended to prefer a non-block (integrated) clinical rotation; citing that the structure better facilitated application of theoretical knowledge in practice, enhanced formative development and feedback from supervising nurses, helped to maintain a better work/life balance and provided more varied patient engagement. Third and fourth-year learners, however, showed a preference for a block model; regarding it as an approach which offered better theoretical preparation prior to placement, allowed the student to exclusively concentrate on clinical learning during the experience, promoted continuity of care, strengthened working relationships with nurses in the practicum and more effectively consolidated and enhanced their clinical skills and decision-making. ${ }^{[3]}$

In Australia, a descriptive, exploratory study by Birks et al. ${ }^{[37]}$ involving focus groups and individual interviews with 22 third-year PRN students to explore the impact of a block versus distributed (integrated) placement model on the student learning experience found both placement modes had 'inherent advantages and disadvantages that might be magnified depending on the individual student's circumstances'. Participants reported that they were more likely to be accepted as a member of the clinical team during a distributed placement and that this model better facilitated an awareness of ward routines, enhanced communication skills acquisition, offered a better work/life balance and facilitated the integration of theory and practice. Nonetheless, a block placement 
was deemed to offer a more realistic and authentic experience of ward activities and the RN role, provided an opportunity for focusing exclusively on practice learning and promoted greater consistency in the teaching and support offered by those nurses supervising students during the practicum.

Further work in Canada by Rohatinsky et al. ${ }^{[12]}$ surveying 141 undergraduate nursing students from 5 universities, 'all of whom had completed at least 1 clinical rotation in any year of their program', and 52 instructors (RNs supporting such students) also found no overall preference for either model across both respondent groups. Once more, learners in the early stages of their course tended to prefer non-block (integrated) placements, whilst those who had progressed further indicated a desire for clinical experiences in blocks and neither model appeared to affect levels of student stress related to practice learning. The researchers concluded that the development of nursing knowledge appeared to be more effectively facilitated by the non-block model, whilst immersion and transitioning into clinical practice was better promoted by block experiences and they therefore recommended that PRN programmes should expose students to both types of practicum.

\section{Conclusion and RECOMmendations}

Although practice learning experience has been widely regarded as a fundamental and resource-intensive component of nursing programmes since the implementation of formal preparatory nurse education in the mid-nineteenth century, most work in this field to date has focused exclusively on the supervisory practices of clinicians and educators, rather than exploring how the duration and intensity of a placement may influence the nature of practice learning. Whilst multiple sub-variants exist, it is argued that there are essentially only three key models used to structure clinical learning experiences in PRN programmes and of these only the block and integrated approaches are primary components of such curricula. Much professional literature recommends longer student practicum experiences but lacks detail as to exactly how longer placements benefit nursing students and such work seldom clarifies whether an extended block placement or a transition to an integrated model of practice learning is being recommended.

Studies evaluating innovative projects offering concurrent paid nursing employment to undergraduate student nurses display similar features to an integrated practicum within a PRN programme, although several key differences limit the extent to which these findings can be applied to such provision. Even where dedicated research has evaluated the implementation of a structural model of practice learning, it often only examines the impact of the new initiative rather than undertaking a comparative analysis in relation to the existing model. Amongst those very limited studies which offer such comparison, there is a lack of consensus regarding the most desirable placement model for a professional practice programme; strengths and limitations being highlighted in respect of both the block and integrated frameworks. Investigation within the field and collation of evidence to begin to formulate best practice in this aspect of curriculum design, however, are adversely affected by inconsistent use of language to describe the same model of placement structure; for example, in this review five alternative terms were identified for an integrated practicum alone. Agreed terminology in respect of such frameworks is therefore vital to consolidate the body of knowledge associated with structural placement models.

There are, nevertheless, some early and modest signs that the most desirable structure and intensity of a practice learning experience may be associated with the student's position within a programme of study and their personal circumstances. Spence et al. ${ }^{[103]}$ maintain that 'different models for clinical learning are appropriate for different contexts and stages of student development', but given the current international paucity of research comparing block and integrated placement models within pre-registration healthcare programmes, it is highly questionable whether there is yet sufficient evidence to present a compelling argument regarding which of these models is most appropriate for specific periods of learner development or what student characteristics more favourably dispose an individual to practice experience within either model. The author is currently undertaking mixed methods research, underpinned by the principles of Critical Realism, to examine the impact of block and integrated practicum frameworks on the learning experiences of mature PRN students at a university in the UK. He therefore looks forward to further developing the body of knowledge within this field of nurse education, recommending changes to future curricula congruent with Critical Realist philosophy and in so doing contributing to improved practice learning experiences.

\section{ACKNOWLEDGEMENTS}

I would like to convey my sincere thanks to Julie Key, Literature Search Specialist in the Library and Archives Services of the RCN for her invaluable assistance in the second phase of the literature search which underpinned this review.

\section{CONFLiCTS OF INTEREST Disclosure}

The author declares that there is no conflict of interest. 


\section{REFERENCES}

[1] Bergjan M, Hertel F. Evaluating students' perception of their clinical placements - Testing the clinical learning environment and supervision and nurse teacher scale (CLES+T scale) in Germany. Nurse Education Today. 2013; 33: 1393-1398. PMid:23200088 https://doi.org/10.1016/j.nedt.2012.11.002

[2] Bourgeois S, Drayton N, Brown A. An innovative model of supportive clinical teaching and learning for undergraduate nursing students: The cluster model. Nurse Education in Practice. 2011; 11: 114-118. PMid:21185231 https ://doi.org/10.1016/j.nepr.2010.11 .005

[3] Rohatinsky N, Chachula K, Compton R, et al. Nursing Student Preference for Block Versus Nonblock Clinical Models. Journal of Nursing Education. 2017; 56(3): 152-157. PMid:28263353 https ://doi.org/10.3928/01484834-20170222-06

[4] Bhagwat M, Hewetson R, Jones L, et al. Comparison of paired and single clinical placement models: a time-use analysis. International Journal of Language \& Communication Disorders. 2018; 53(3): 468-479. PMid:29218762 https ://doi.org/10.1111/14 60-6984. 12360

[5] Levett-Jones T, Bowen L, Simmons C, et al. The professional nursing and construction curricula in Simmons, C., Williams, A., Sher, S. \& Levett-Jones, T. (Eds) Work Ready. E-Portfolios to Support Professional Placements. Office for Learning and Teaching: Sydney, Australia; 2012.

[6] Patterson C, Moxham L, Taylor E, et al. Effect of immersive workplace experience on undergraduate nurses' mental health clinical confidence. International Journal of Mental Health Nursing. 2017; 26: 620-628. PMid:28160371 https://doi.org/10.1111/inm. 12288

[7] Ousey K. The changing face of student nurse education and training programmes. Wounds UK. 2011; 7(1): 70-76.

[8] Jack K, Hamshire C, Harris W, et al. "My mentor didn't speak to me for the first four weeks": Perceived Unfairness experienced by nursing students in clinical practice settings. Journal of Clinical Nursing. 2018; 27: 929-938. PMid:28815761 https ://doi .org/10.1111/ jocn. 14015

[9] Papastavrou E, Dimitriadou M, Tsangari H, et al. Nursing students' satisfaction of the clinical learning environment: a research study. BMC Nursing, 2016; 15(44): 1-10. PMid:27436992 https : //doi.org/10.1186/s12912-016-0164-4

[10] Perry R, Press M, Rohatinsky N, et al. Pilot study: Nursing students' perceptions of the environment in two different clinical models. International Journal of Nursing Sciences. 2016; 3: 285-290. https://doi.org/10.1016/j.ijnss.2016.07.001

[11] Chan A, Tang F, Choi K, et al. Clinical learning experiences of nursing students using an innovative clinical partnership model: A nonrandomized controlled trial. Nurse Education Today. 2018; 68: 121127. PMid:29902741 https://doi.org/10.1016/j.nedt. 201 8.06 .001

[12] Jayasekara R, Smith C, Hall C, et al. The effectiveness of clinical education models for undergraduate nursing programs: A systematic review. Nurse Education in Practice. 2018; 29: 116-126. PMid:29272736 https ://doi.org/10.1016/j.nepr.2017.12 .006

[13] Martin M, Morris J, Moore A, et al. Evaluating Practice Education Models in Occupational Therapy: Comparing 1:1, 2:1 and 3:1 Placements. British Journal of Occupational Therapy. 2004; 67(5): 192-200. https://doi.org/10.1177/030802260406700502

[14] Cleak H, Smith D. Student Satisfaction with Models of Field Placement Supervision. Australian Social Work. 2012; 65(2): 243-258. https ://doi.org/10.1080/0312407X.2011.572981
[15] O’Connor A, Cahill M, McKay E. Revisiting 1:1 and 2:1 clinical placement models: Student and clinical educator perspectives. Australian Occupational Therapy Journal. 2012; 59: 276-283. PMid:22934900 https://doi .org/10.1111/j.1440-1630.20 $12.01025 . \mathrm{x}$

[16] Greenstock L, Brooks P. Medical students' perceptions of role models on clinical placements. The Clinical Teacher. 2014; 11: 104-108. PMid:24629246 https://doi.org/10.1111/tct.12063

[17] Fairbrother M, Nicole M, Blackford J, et al. A new model of clinical education to increase student placement availability: The capacity development facilitator model. Asia-Pacific Journal of Cooperative Education. 2016; 17(1): 45-59. https://doi.org/10.17509/j apanedu.v1i2.3285

[18] Sheepway L, Lincoln M, Togher L. An international study of clinical education practices in speech-language pathology, International Journal of Speech-Language Pathology. 2011; 13(2): 174185. PMid:20626316 https://doi.org/10.3109/17549507.2 011.491129

[19] Uys L, Gwele N. Curriculum Development in Nursing. Process and Innovations. Routledge: Abingdon, England; 2005.

[20] Donnelly F. The influence of clinical placement and experiential learning on student nurse development: an exploratory case study. Doctoral Thesis, University of Adelaide, Australia; 2012.

[21] Thomas M, Westwood N. Student experience of hub and spoke model of placement allocation - An evaluative study. Nurse Education Today. 2016; 46: 24-28. PMid:27586029 https ://doi .org/10.101 $6 / \mathrm{j} \cdot$ nedt .2016 .08 .019

[22] McClimens A, Brewster J. Using the hub and spoke student placement model in learning disability settings. Learning Disability Practice. 2017; 20(3): 34-38. https ://doi.org/10.7748/1dp. 2017 . e1832

[23] Stacey G, Felton A, Bonham P. Placement learning in Mental Health Nursing. A guide for students in practice. Bailliere Tindall Elsevier: Edinburgh, Scotland; 2012.

[24] Roxburgh C, Conlon M, Banks D. Evaluating Hub and Spoke models of practice learning in Scotland, UK: A multiple case study approach. Nurse Education Today. 2012; 32: 782-789. PMid:22683178 https ://doi.org/10.1016/j.nedt.2012.05.004

[25] Venkatesan L, Joshi P. Textbook of Nursing Education. Reed Elsevier India: New Delhi, India; 2015.

[26] Stephenson N. Strengthening students' engagement in active participation to learn practical skills through workplacements: a case study of Kiwoko Medical Laboratory Training School in Nakaseke District. Masters Thesis, Kyambogo University, Uganda; 2016.

[27] Callaghan D, Watts W, McCullough D, et al. The experience of two practice education models: Collaborative learning unit and preceptorship. Nurse Education in Practice. 2009; 9: 244-252. PMid:18948062 https ://doi.org/10.1016/j.nepr.2008.08.010

[28] Cooper Brathwaite A, Lemonde M. Team Preceptorship Model: A Solution for Students' Clinical Experience, International Scholarly Research Network Nursing. 2011; 1-7. PMid:21994893 https : //doi.org/10.5402/2011/530357

[29] Cleak H, Zuchowski I. Empirical Support and Considerations for Social Work Supervision of Students in Alternative Placement Models. Clinical Social Work Journal. 2019; 47: 32-42. https : //doi.org/10.1007/s10615-018-0692-3

[30] Happell B, Gaskin C, Byrne L, et al. Clinical Placements in Mental Health: A Literature Review, Issues in Mental Health Nursing. 2015; 36(1): 44-51. PMid:25397660 https ://doi .org/10.3109/0161 2840.2014 .915899 
[31] Ryan G, Toohey S, Hughes C. The purpose, value and structure of the practicum education: a literature review. Higher Education. 1996; 31: 355-377. https://doi .org/10.1007/BF00128437

[32] Kevin J, Callaghan A, Driver C, et al. A possible alternative model of clinical experience for student nurses. Journal for Nurses in Staff Development. 2010; 26(5): e5-e9. PMid:20885138 https: //doi.org/10.1097/NND.0b013e3181b1ba07

[33] Shiverick D. Chapter 2. Describing undergraduate placements. A Full-Time Clinical Practicum for Undergraduates in Ware, M. Millard, R. (eds) Handbook on Student Development. Advising, Career Development, and Field Placement. eBook. Routledge: New York, USA; 2012.

[34] Thistlethwaite J, Bartle E, Chong A, et al. A review of longitudinal community and hospital placements in medical education: BEME Guide No.26. Medical Teacher. 2013; 35(8): e1340e1364. PMid:23848374 https://doi.org/10.3109/0142159x .2013.806981

[35] Levett-Jones T, Bourgeois S. The clinical placement. An essential guide for nursing students. 2nd ed. Elsevier Australia: Chatswood, Australia; 2011.

[36] Coghill E. An evaluation of how trainee nursing associates (TNAs) balance being a 'worker' and a 'learner' in clinical practice: an early experience study. Part 2/2. British Journal of Healthcare Assistants. 2018; 12(7): 356-359. https ://doi.org/10.12968/bjha. 2018 .12 .7 .356

[37] Birks M, Burkot C, Bagley T, et al. The impact of clinical placement model on learning in nursing: A descriptive exploratory study. Australian Journal of Advanced Nursing. 2017; 34(3): 16-23.

[38] Reinke N. The impact of timetable changes on student achievement and learning experiences. Nurse Education Today. 2018; 62: 137-142. PMid:29353087 https ://doi.org/10.1016/j.nedt.2017.12 .015

[39] Sala-Hamrick K. "Please, Sir, May I Have Some More?" How to Get the Most Hours Out of Your Clinical Placement, Time to Track. 2019. Available from: http://blog.time2track.com/please -sir-may-i-have-some-more-how-to-get-the-most-hou rs-out-of-your-clinical-placement/

[40] Boardman G, Lawrence K, Polacsek M. Undergraduate student nurses' perspectives of an integrated clinical learning model in the mental health environment. International Journal of Mental Health Nursing. 2019; 28: 96-104. PMid:29897671 https ://doi .org/10 $.1111 /$ inm. 12496

[41] Ranse K, Grealish L. Nursing students' perceptions of learning in the clinical setting of the Dedicated Education Unit. Journal of Advanced Nursing. 2007; 58(2): 171-179. PMid:17445020 https: //doi.org/10.1111/j.1365-2648.2007.04220.x

[42] Diefenbeck C, Plowfield L, Herrman J. Clinical Immersion. A Residency Model for Nursing Education. Nursing Education Perspectives. 2006; 27(2): 72-79.

[43] Wildermuth M, Weltin A, Simmons A. Transition experiences of nurses as students and new graduate nurses in a collaborative nurse residency program. Journal of Professional Nursing. 2020; 36: 69-75 PMid:32044057 https://doi.org/10.1016/j.profnurs. 201 9.06 .006

[44] Paulson C. The Experiences of Faculty Teaching in an Innovative Clinical Immersion Curriculum. Nursing Education Perspectives. 2011; 32(6): 395-399. PMid:22235697 https://doi.org/10.5 480/1536-5026-32.6.395

[45] Diefenbeck C, Herrman J, Wade G, et al. Preparedness for Clinical: Evaluation of the Core Elements of the Clinical Immersion Curriculum Model. Journal of Professional Nursing. 2015; 31(2): 124-132.
PMid:25839952 https://doi.org/10.1016/j.profnurs. 201 4.08 .004

[46] Keiffer M, Loomis J. Goyal, D. Nurse Practitioner Student Clinical Placements: A Rural Community Immersion. The Journal for Nurse Practitioners. 2020; 16: e1-e4. https ://doi.org/10.1016/j.nu rpra.2019.10.002

[47] Saxton R, Nauser J. Students' experiences of clinical immersion in operating room and emergency department. Nurse Education in Practice. 2020; 43: 1-5. PMid:32001427 https ://doi.org/10.1016/ j.nepr. 2020.102709

[48] West N, Wallace J, Fuller R. Chapter 2. Bridging the AcademicPractice Gap in Nursing In; Huston, C. Professional Issues in nursing: challenges and opportunities. 5th ed. Wolters Kluwer: Philadelphia, USA; 2020.

[49] Aloweni F, Teh A, Tan S, et al. Promoting research competence: introduction of the nursing research immersion program in Singapore General Hospital. Proceedings of Singapore Healthcare. 2017; 26(4): 267-269. https ://doi .org/10.1177/2010105817697734

[50] Bridge P, Carmichael M. Factors influencing radiation therapy student clinical placement satisfaction. Journal of Medical Radiation Sciences. 2014; 61: 45-50. PMid:26229635 https ://doi .org/10 .1002/jmrs. 41

[51] Zomorodi M, de Saxe Zerden L, Nance-Floyd B, et al. Impact of an interprofessional population health course and clinical immersion experience: Students and practice outcomes. Journal of Interprofessional Education \& Practice. 2020; 9: 91-94. https : //doi.org/10.1016/j.xjep.2017.08.008

[52] Wallace J. Nursing Student Work-Study Internship Program: An Academic Partnership. Journal of Nursing Education. 2016; 55(6): $357-$ 359. PMid:27224467 https://doi .org/10.3928/01484834-2 0160516-11

[53] Doerner M. Perioperative Clinical Immersion. Journal of PeriAnesthesia Nursing. 2017; 32(4): e41. https: //doi.org/10.1016/j. jopan. 2017.06 .006

[54] Doerner M, Swenty C. The Effect of a Perioperative Clinical Immersion on Senior Nursing Students' Perception of Readiness to Practice: A Quality Improvement Project. AORN Journal. 2019; 109(2): 193200. PMid:30694533 https://doi.org/10.1002/aorn. 12581

[55] Neal-Boylan L. Immersion Clinical Experience for NP Students? The Journal for Nurse Practitioners. 2019; A7-8. https ://doi .or g/10.1016/j.nurpra.2019.10.019

[56] Kumm S, Godgrey N, Richards V, et al. Senior student nurse proficiency: A comparative study of two clinical immersion models. Nurse Education Today. 2016; 44: 146-150. PMid:27429344 https://doi.org/10.1016/j.nedt. 2016.05.023

[57] Amorin-Woods L, Lasco B, Leach M. A mixed-method study of chiropractic student clinical immersion placements in nonmetropolitan Western Australia: Influence on student experience, professional attributes, and practice destination. Journal of Chiropractic Education. 2019; 33(1): 30-39. PMid:30444636 https ://doi.org/10.789 9/jce-18-1

[58] Rudland J, Tordoff R, Reid J, et al. The clinical skills experience of rural immersion medical students and traditional hospital placement students: A student perspective. Medical Teacher. 2011; 33: e435439. PMid:21774640 https://doi.org/10.3109/0142159X. 2 011.586745

[59] Bhaskar R. A Realist Theory of Science. Taylor \& Francis e-Library Edition. Routledge: Abingdon, England; 2008.

[60] Terry K. The competency landscape: a critical realist exploration of the ways nurses understand and utilise competency standards. Doctoral Thesis, University of Tasmania; 2013. 
[61] Schiller C. Critical realism in nursing: an emerging approach. Nursing Philosophy. 2016; 17(2): 88-102. PMid:26608357 https : //doi.org/10.1111/nup.12107

[62] Smith M. Overcoming theory-practice inconsistencies: Critical realism and information systems research. Information and Organization. 2006; 16(3): 191-211. https://doi.org/10.1016/j.infoando rg. 2005.10.003

[63] Clark A, Lissel S, Davis C. Complex critical realism: tenets and application in nursing research. Advances in Nursing Science. 2008; 31(4): E67-79. PMid:19033741 https://doi.org/10.1097/01 . ANS. $0000341421.34457 .2 \mathrm{a}$

[64] Hammersley M. Research as Emancipatory. Journal of Critical Realism. 2002; 1(1): 33-48. https://doi.org/10.1558/jocr.v1i1. 33

[65] Patomaki H, Wight C. After Postpositivism? The Promises of Critical Realism. International Studies Quarterly. 2000; 44: 213-237. https://doi .org/10.1111/0020-8833.00156

[66] Wikgren M. Critical realism as a philosophy and social theory in information science? Journal of Documentation. 2005; 61(1): 11-22. https://doi.org/10.1108/00220410510577989

[67] Houston S. Beyond social constructionism: critical realism and social work. British Journal of Social Work. 2001; 31(6): 845-861. https://doi.org/10.1093/bjsw/31.6.845

[68] McGhee P, Grant P. Applying critical realism in spirituality at work research. Management Research Review. 2017; 40(8): 845-869. https://doi.org/10.1108/MRR-05-2016-0124

[69] Perversi P, Yearwood J, Bellucci E, et al. Exploring reasoning mechanisms in ward rounds: a critical realist multiple case study. BMC Health Services Research. 2018; 18(643): 1-11. PMid:30119624 https://doi.org/10.1186/s12913-018-3446-6

[70] Shajimon P, Soon-Chean P. Changing research methodology: Two case studies of critical realism informing social work doctoral research. Aotearoa New Zealand Social Work. 2018; 30(1): 65-70. https://doi.org/10.11157/anzswj-vol30iss1id426

[71] Ranyard R. A Critical Realist Perspective on Decisions Involving Risk and Uncertainty. Polish Psychological Bulletin. 2014; 45(1): 3-11. https://doi.org/10.2478/ppb-2014-0002

[72] Frecknall-Hughes J. Research Methods in Taxation History. Review of Behavioral Economics. 2016; 3(1): 5-20. https://doi.org/10 $.1561 / 105.00000041$

[73] Parlour R, McCormack B. Blending critical realist and emancipatory practice development methodologies: making critical realism work in nursing research. Nursing Inquiry. 2012; 19(4): 308-321. PMid:21992448 https://doi .org/10.1111/j.1440-1800.20 $11.00577 . \mathrm{x}$

[74] Parpio Y, Malik S, Punjani N, et al. Critical Realism: Tenets and Application in Nursing. International Journal of Innovative Research \& Development. 2013; 2(11): 490-493.

[75] Newton J, Jolly B, Ockerby C, et al. Clinical learning environment inventory: factor analysis. Journal of Advanced Nursing. 2010; 66(6): 1371-1381. PMid:20546367 https://doi.org/10.1111/ j.1365-2648.2010.05303.x

[76] Tomietto M, Comparcini D, Saarikoski M, et al. Multilevel perspectives in clinical learning environments' assessment: An insight on levels involved in planning nursing education. Journal of Nurse Education and Practice. 2014; 4(12): 42-50. https://doi.org/10.5 430/jnep.v4n12p42

[77] Dafogianni C, Alikari V, Galanis P, et al. Nursing Students' Views on their Clinical Placement in Pediatric Hospitals of Athens, Greece. International Journal of Caring Sciences. 2015; 8(3): 673-682.
[78] Roberts J. Critical Realism, Dialectics, and Qualitative Research Methods, Journal for the Theory of Social Behaviour. 2014; 44: 1-23. https://doi.org/10.1111/jtsb. 12056

[79] Jones-Devitt S, Austen L, Parkin H. Integrative Reviewing for exploring complex phenomena. Social Research Update. 2017; 66 (Spring): 1-4. http://shura.shu.ac.uk/id/eprint/16571

[80] Edgley A, Stickley T, Timmons S, et al. Critical realist review: exploring the real, beyond the empirical. Journal of Further and Higher Education. 2016; 40(3): 316-330. https://doi.org/10.1080/ 0309877X.2014.953458

[81] Coleman P. A Critical Realist review of practice learning experiences within pre-registration nursing programmes. EAS Journal of Nursing and Midwifery. 2020; 2(6): 202-212.

[82] Clegg S. Chapter 12: Is computing really for women? A critical realist approach to gender issues in computing In: Lopez, J. Potter, G. (eds.) After Postmodernism. An introduction to Critical Realism. The Athlone Press: London, England; 2001.

[83] Victor L. Systematic reviewing. Social Research Update. 2008; 54(Summer): 1-4.

[84] O'Mahoney J, Vincent S. Chapter 1. Critical Realism as an empirical project: a beginner's guide. In: Edwards, P., O'Mahoney, J. Vincent, S. (eds), Studying organizations using critical realism. A practical guide. Oxford University Press, England; 2014. https: //doi.org/10.1093/acprof : oso/9780199665525.003.0001

[85] Bonine K, Oh K. Critical Evaluation of a Published Paper. 2006. Available from: http://eebweb.arizona.edu/courses/Ecol4 37/CriticallyEvaluatingScientificPapers2006. doc

[86] Donnelly F, Wiechula R. Clinical placement and case study methodology: A complex affair. Nurse Education Today. 2012; 32: 873-877. PMid:22436427 https://doi.org/10.1016/j .nedt.2012.02 .010

[87] Phillips J. Student nurses' lived experiences of their last practice placement. Doctoral Thesis. Bournemouth University, England; 2017.

[88] National Nursing and Nursing Education Taskforce A report on Commonwealth funding to support the costs of clinical practicum for undergraduate nurses and midwives in Australia. Australian Health Ministers' Advisory Council: Melbourne, Australia; 2006.

[89] Sheepway L, Lincoln M, McAllister S. Impact of placement type on the development of clinical competency in speech-language pathology students. International Journal of Language \& Communication Disorders. 2014; 49(2): 189-203. PMid:24182204 https : //doi.org/10.1111/1460-6984.12059

[90] Nolan C. Learning on clinical placement: the experience of six Australian student nurses. Nurse Education Today. 1998; 18: 622-629. https://doi.org/10.1016/S0260-6917(98)80059-2

[91] Evans W, Kelly B. Pre-registration diploma student nurse stress and coping measures. Nurse Education Today. 2004; 24: 473-482. PMid:15312957 https://doi.org/10.1016/j.nedt.2004.05 .004

[92] Levett-Jones T, Lathlean J, Higgins I. McMillan, M. The duration of clinical placements: a key influence on nursing students' experience of belongingness. Australian Journal of Advanced Nursing. 2008; 26(2): 8-16.

[93] Warne T, Johansson U, Papastavrou E, et al. An exploration of the clinical learning experience of nursing students in nine European countries. Nurse Education Today. 2010; 30: 809-815. PMid:20409620 https://doi.org/10.1016/j.nedt.2010.03 .003

[94] Killam L, Heerschap C. Challenges to student learning in the clinical setting: A qualitative descriptive study. Nurse Education Today. 
2013; 33: 6841-691. PMid:23141689 https ://doi.org/10.101 $6 / j . n e d t .2012 .10 .008$

[95] Bjork I, Berntsen K, Brynilsen G, et al. Nursing students' perceptions of their clinical learning environment in placements outside traditional hospital settings. Journal of Clinical Nursing. 2014; 23(1920): 2958-2967. PMid:24460862 https://doi.org/10.1111/jo cn. 12532

[96] Carlson E, Idvall E. Nursing students' experiences of the clinical learning environment in nursing homes: A questionnaire study using the CLES + T evaluation scale. Nurse Education Today. 2014; 34: 1130-1134. PMid:24529997 https://doi.org/10.1016/j. nedt. 2014.01 .009

[97] Playford D, Larson A, Wheatland B. Going country: Rural student placement factors associated with future rural employment in nursing and allied health. Australian Journal of Rural Health. 2006; 14: 14-19 PMid:16426427 https ://doi.org/10.1111/j.1440-1584.20 $06.00745 . \mathrm{x}$

[98] McDonnel Smedts A, Lowe M. Efficiency of clinical training at the Northern Territory Clinical School: placement length and rate of return for internship. Medical Journal of Australia. 2008; 189: 166-168. https://doi.org/10.5694/j.1326-5377.2008.tb01953.x

[99] Chan P. FAIRness and clinical teaching. Medical Teacher. 2013; 35(9): 779-781. PMid:23782052 https ://doi.org/10.3109/01 42159X. 2013.799639

[100] Hudson J, Weston K. Chapter 25. The Benefits of Longitudinal Relationships with Patients for Developing Health Professionals in in Higgs, J., Croker, A., Tasker, D., Hummell, J. \& Patton, N. (eds.) Health Practice Relationships. Sense Publishers: Rotterdam, The Netherlands; 2014.

[101] Mihalynuk T, Bates J, Page G, et al. Student learning experiences in a longitudinal clerkship programme. Medical Education. 2008; 42: 729-732. PMid:18588652 https ://doi.org/10.1111/j.13 65-2923.2008.03040.x

[102] Poncelet A, Hudson J. Student Continuity with Patients: A System Delivery Innovation to Benefit Patient Care and Learning (Continuity Patient Benefit). Healthcare. 2015; 3: 607-618. PMid:27417783 https://doi.org/10.3390/healthcare3030607
[103] Spence D, Zambas S, Mannix J, et al. Challenges to the provision of clinical education in nursing. Contemporary Nurse. 2019; 55(45): 458-467. PMid:30987540 https : //doi .org/10.1080/1037 6178.2019 .1606722

[104] Gamroth L, Budgen C, Lougheed M. Feasibility and outcomes of paid undergraduate student nurse positions. Nursing Leadership. 2006; 19(3): e1-e14. PMid:19830923 https ://doi.org/10.129 $27 /$ cjnl.2006. 19032

[105] McLachlan H, Forster D, Ford R, et al. Addressing the midwifery workforce crisis: Evaluating an employment model for undergraduate midwifery students at a tertiary maternity hospital in Melbourne, Australia. Women and Birth. 2011; 24: 173-179. PMid:21273152 https://doi.org/10.1016/j.wombi.2010.12.004

[106] Kenny A, Dickson-Swift V, DeVecchi N, et al. Final Report. Evaluation of Registered Undergraduate Student of Nursing (RUSON) Pilot Program. La Trobe University: Melbourne, Australia; 2019.

[107] Carter R. PNs: Facilitators of learning? Practice Nursing. 1997; 8(19): 14-16. https://doi.org/10.12968/pnur.1997.8.19. 14

[108] Gilmour C, McIntyre M, McLelland G, et al. Exploring the impact of clinical placement models on undergraduate midwifery students. Women and Birth. 2013; 26: e21-e25. PMid:22819545 https://doi.org/10.1016/j.wombi.2012.06.004

[109] Boardman G, Lawrence K, Polacsek M. Preceptors' perspectives of an integrated clinical learning model in a mental health environment., International Journal of Mental Health Nursing. 2018; 27: 1420-1429. PMid:29441663 https ://doi.org/10.1111/inm. 12441

[110] Coghill E. An evaluation of how trainee nursing associates (TNAs) balance being a 'worker' and a 'learner' in clinical practice: an early experience study. Part 1/2. British Journal of Healthcare Assistants. 2018; 12(6): 280-286. https://doi.org/10.12968/bjha. 2018 .12 .6 .280

[111] Vanson T, Bidey T. Introduction of Nursing Associates. Year 2 Evaluation Report. Health Education England: London, England. 2019.

[112] Rohatinsky N, Chachula K, Sedgwick M, et al. Comparison of Nursing Student and Instructor Preferences for Block and Nonblock Clinical Models. Nurse Educator. 2018; 43(4): E1-E6. PMid:28991032 https://doi.org/10.1097/NNE.0000000000000458 